\title{
COMMENTARY
}

\section{Appropriate antibiotic dosing in severe sepsis and acute renal failure: factors to consider}

\author{
Francisco Javier González de Molina' and Ricard Ferrer*1,2 \\ See related research by Seyler et al., http://ccforum.com/content/15/3/R137
}

\begin{abstract}
Severe sepsis and septic shock cause considerable morbidity and mortality. Early appropriate empiric broad-spectrum antibiotics and advanced resuscitation therapy are the cornerstones of treatment for these conditions. In prescribing an antibiotic regimen in septic patients with acute renal failure treated with continuous renal replacement therapy, several factors should be considered: pharmacokinetics, weight, residual renal function, hepatic function, mode of renal replacement therapy (membrane and surface area, sieving coefficient, effluent and dialysate rate, and blood flow rate), severity of illness, microorganism, minimum inhibitory concentration, and others. Studies that determine the serum antibiotic concentrations are very useful in establishing the correct dosage in critical patients.
\end{abstract}

Inappropriate antimicrobial therapy refers not only to an unsuitable drug choice in terms of spectrum of activity but also to an inadequate dosing regimen. With this in mind, Seyler and colleagues [1] conducted a prospective study in order to determine whether recommended $\beta$ lactam regimens ensure appropriate phamacokinetic/ pharmacodynamic exposure against Pseudomonas aeruginosa in septic patients treated with continuous renal replacement therapy (CRRT).

Severe sepsis and septic shock cause significant morbidity and mortality. Early appropriate empiric broadspectrum antibiotics and advanced resuscitation therapy are the cornerstones of treatment for these conditions [2]. Acute kidney injury requiring renal replacement therapy occurs in $5 \%$ to $6 \%$ of critical patients. These

*Correspondence: rferrer@mutuaterrassa.es

${ }^{1}$ Critical Care Department, Mutua Terrassa University Hospital, University of

Barcelona, Plaça Dr. Robert, 5, Terrassa 08221, Barcelona, Spain

Full list of author information is available at the end of the article patients use significant resources and up to $60 \%$ die from their injuries [3]. Optimized antibiotic dosing may help reduce this burden; however, data to guide dosing in patients with severe sepsis/septic shock and multiple organ dysfunction under CRRT are scant. Antibiotic dosing in these conditions is complicated, and incorrect dosage may result in drug toxicity or treatment failure and resistance.

Antibacterial pharmacokinetics are affected by CRRT and may be altered by acute renal failure and critical illness [4]. Recommendations for patients who have chronic renal failure and who are undergoing intermittent hemodialysis are not appropriate for the critically ill, because of differences in the mode of renal replacement therapy and in pharmacokinetics [5]. The optimal dose of antibiotics is usually based on theoretical considerations derived from data from non-critical patients (healthy individuals or those with chronic renal failure with dosage adjustment based on creatinine clearance) [6]. Many studies that focus on calculating the dosing regimen in critical patients fail to consider basic pharmacokinetic parameters like volume of distribution (Vd), protein binding, weight, residual renal function, hepatic function, mode of CRRT, membrane and surface area, sieving coefficient, effluent and dialysate rate, blood flow rate, and severity of illness. Various dose adjustment equations have been proposed for critical patients requiring CRRT. These assume either that measurement of antibiotic concentrations is widely available or that the sieving coefficient can be accurately estimated from data on protein binding obtained from non-critical patients. Only unbound antibiotic is pharmacologically active, but serum protein levels in critical patients vary considerably, so the proportion of unbound drug is unpredictable $[7,8]$.

CRRT is sometimes initiated early in septic patients without unduly impaired renal function to facilitate water balance control. In these circumstances, the creatinine clearance can be substantially maintained $[9,10]$. If we add the clearance of the extracorporeal circuit, the dose must be adjusted to avoid underdosage. Critical patients can have hepatic dysfunction but hepatic 
drug clearance may actually increase in patients with acute renal failure, so hepatic function should also be considered [11].

The modality and dosage of CRRT in critical patients vary widely both between and within studies. Likewise, a patient may undergo different modalities, blood and ultrafiltration flows may vary, and the prescribed dose could differ from the current dose. Changes in CRRT modality, blood flow, ultrafiltration rate, or location of fluid replacement require dose adjustments, and interrupting CRRT because of multiple filter clotting or for surgical or image procedures may affect plasma drug removal. Adsorption of antibiotics on the filter may also result in drug elimination. The clinical importance of $\beta$ lactam adsorption is unknown. Moreover, recent modifications to CRRT, including high-volume hemofiltration, high-adsorption hemofiltration, high-cutoff membranes, and hybrid systems like coupled plasma filtration absorbance, increase $\beta$-lactam elimination [12].

$\beta$-lactams have low molecular weights, low Vd (0.3 to $0.4 \mathrm{~L} / \mathrm{kg}$ ), and relatively low protein binding ( $10 \%$ to $68 \%$ ). Nearly all are excreted primarily unchanged via glomerular filtration. Thus, hemofiltration removes $\beta$-lactams, so CRRT requires dosage adjustments. $\beta$-lactams have timedependent bactericidal activity and a slow continuous bactericidal effect. Their effectiveness depends on how long the serum concentration exceeds a threshold (four to five times the minimum inhibitory concentration $(\mathrm{MIC})$ ). Depending on the target organism and the choice of $\beta$-lactams, the serum concentration should exceed the threshold during $40 \%$ to $100 \%$ of the dosing interval. This is particularly important for life-threatening pathogens potentially resistant to multiple antibiotics as intermittent dosing may allow drug concentrations to fall below the MIC [13]. Continuous or extended infusion could maximize the pharmacodynamics of $\beta$-lactams [14]. Finally, tissue concentrations differ from plasma concentrations and vary among antibiotics [15].

Given the number of variables to consider for antibiotic prescription in critical patients undergoing CRRT and the deleterious impact of underdosage, data from real patients are important. Studies should focus on infections with high intensive care unit incidence caused by germs with high multi-antibiotic resistance, as in the article by Seyler and colleagues [1]. By determining serum concentrations of $\beta$-lactam antibiotics in patients with sepsis and renal failure under CRRT, these authors confirmed that antibiotic dosage is often insufficient in this setting. These findings are clinically relevant: the authors recommend not reducing the dose of $\beta$-lactams during the first 48 hours and monitoring pharmacokinetics thereafter. More studies like this are needed to evaluate the appropriate dosage of other antibiotics in patients with acute renal failure and severe sepsis.

\section{Abbreviations}

CRRT, continuous renal replacement therapy; MIC, minimum inhibitory concentration; $\mathrm{Vd}$, volume of distribution.

\section{Competing interests}

The authors declare that they have no competing interests.

\section{Author details}

${ }^{1}$ Critical Care Department, Mutua Terrassa University Hospital, University of Barcelona, Plaça Dr. Robert, 5, Terrassa 08221, Barcelona, Spain. ${ }^{2} \mathrm{CIBER}$, Enfermedades Respiratorias, Fundaci d Investigaci Sanit ria de les Illes Balears (FISIB), Recinto Hospital Joan March, Carretera Soller Km 12 07110, Bunyola, Mallorca, Illes Balears.

Published: 1 August 2011

\section{References}

1. Seyler L, Cotton F, Taccone FS, De Backer D, Macours P, Vincent JL, Jacobs F: Recommended beta-lactam regimens are inadequate in septic patients treated with continuous renal replacement therapy. Crit Care 2011, 15:R137.

2. Garnacho-Montero J, Ortiz-Leyba C, Herrera-Melero I, Aldabo-Pallas T, Cayuela-Dominguez A, Marquez-Vacaro JA, Carbajal-Guerrero J, GarciaGarmendia JL: Mortality and morbidity attributable to inadequate empirical antimicrobial therapy in patients admitted to the ICU with sepsis: a matched cohort study. J Antimicrob Chemother 2008, 61:436-441.

3. Uchino S, Kellum JA, Bellomo R, Doig GS, Morimatsu H, Morgera S, Schetz M, Tan I, Bouman C, Macedo E, Gibney N, Tolwani A, Ronco C; Beginning and Ending Supportive Therapy for the Kidney (BEST Kidney) Investigators: Acute renal failure in critically ill patients: a multinational, multicenter study. JAMA 2005, 294:813-818.

4. Roberts JA, Lipman J: Pharmacokinetic issues for antibiotics in the critically ill patient. Crit Care Med 2009, 37:840-851; quiz 859.

5. Trotman RL, Williamson JC, Shoemaker DM, Salzer WL: Antibiotic dosing in critically ill adult patients receiving continuous renal replacement therapy. Clin Infect Dis 2005, 41:1159-1166.

6. Schetz M, Ferdinande P, Van den Berghe G, Verwaest C, Lauwers P: Pharmacokinetics of continuous renal replacement therapy. Intensive Care Med 1995, 21:612-620.

7. Golper TA, Marx MA: Drug dosing adjustments during continuous renal replacement therapies. Kidney Int Supp/ 1998, 66:S165-168.

8. Bugge JF: Pharmacokinetics and drug dosing adjustments during continuous venovenous hemofiltration or hemodiafiltration in critically ill patients. Acta Anaesthesiol Scand 2001, 45:929-934.

9. Bagshaw SM, Bellomo R, Devarajan P, Johnson C, Karvellas CJ, Kutsiogiannis DJ, Mehta R, Pannu N, Romanovsky A, Sheinfeld G, Taylor S, Zappitelli M, Gibney RT: Review article: renal support in critical illness. Can J Anaesth 2010, 57:999-1013.

10. Basso F, Ricci Z, Cruz D, Ronco C: International survey on the management of acute kidney injury in critically ill patients: year 2007. Blood Purif 2010, 30:214-220.

11. Pea F, Viale P, Pavan F, Furlanut M: Pharmacokinetic considerations for antimicrobial therapy in patients receiving renal replacement therapy. Clin Pharmacokinet 2007, 46:997-1038.

12. Cerda J, Ronco C: Modalities of continuous renal replacement therapy: technical and clinical considerations. Semin Dial 2009, 22:114-122.

13. DeRyke CA, Lee SY, Kuti JL, Nicolau DP: Optimising dosing strategies of antibacterials utilising pharmacodynamic principles: impact on the development of resistance. Drugs 2006, 66:1-14.

14. Mouton JW, Vinks AA: Continuous infusion of beta-lactams. Curr Opin Crit Care 2007, 13:598-606.

15. Joukhadar C, Frossard M, Mayer BX, Brunner M, Klein N, Siostrzonek P, Eichler HG, Muller M: Impaired target site penetration of beta-lactams may account for therapeutic failure in patients with septic shock. Crit Care Med 2001, 29:385-391.

\section{doi:10.1186/cc10298}

Cite this article as: González de Molina FJ, Ferrer R: Appropriate antibiotic dosing in severe sepsis and acute renal failure: factors to consider. Critical Care 2011, 15:175. 